\title{
Dichloroacetate inhibits aerobic glycolysis in multiple myeloma cells and increases sensitivity to bortezomib
}

\author{
W Y Sanchez ${ }^{*, 1,5}$, S L McGee ${ }^{2}$, T Connor ${ }^{2}$, B Mottram ${ }^{3}$, A Wilkinson ${ }^{1}$, J P Whitehead ${ }^{1}$, S Vuckovic ${ }^{1,4,6,7}$ \\ and L Catley ${ }^{1,7}$ \\ ${ }^{1}$ Mater Medical Research Institute, South Brisbane 4101, Queensland, Australia; ${ }^{2}$ Metabolic Research Unit, School of Medicine, \\ Deakin University, Waurn Ponds 3217, Victoria, Australia; ${ }^{3}$ Queensland Health Pathology Service, Mater Adults Hospital, Brisbane \\ 4101, Queensland, Australia and ${ }^{4}$ School of Medicine, The University of Queensland, Herston, 4006, Queensland, Australia
}

Background: Dichloroacetate (DCA), through the inhibition of aerobic glycolysis (the 'Warburg effect') and promotion of pyruvate oxidation, induces growth reduction in many tumours and is now undergoing several clinical trials. If aerobic glycolysis is active in multiple myeloma (MM) cells, it can be potentially targeted by DCA to induce myeloma growth inhibition.

Methods: Representative multiple myeloma cell lines and a myeloma-bearing mice were treated with DCA, alone and in combination with bortezomib.

Results: We found that aerobic glycolysis occurs in approximately half of MM cell lines examined, producing on average 1.86-fold more lactate than phorbol myristate acetate stimulated-peripheral blood mononuclear cells and is associated with low-oxidative capacity. Lower doses of DCA (5-10 mM) suppressed aerobic glycolysis and improved cellular respiration that was associated with activation of the pyruvate dehydrogenase complex. Higher doses of DCA (10-25 mM) induced superoxide production, apoptosis, suppressed proliferation with $\mathrm{G}_{0 / 1}$ and $\mathrm{G}_{2} \mathrm{M}$ phase arrest in $\mathrm{MM}$ cell lines. In addition, DCA increased MM cell line sensitivity to bortezomib, and combinatorial treatment of both agents improved the survival of myeloma-bearing mice.

Conclusion: Myeloma cells display aerobic glycolysis and DCA may complement clinically used MM therapies to inhibit disease progression.

Cancer cells possess a near-universal metabolic phenotype known as the 'Warburg effect', which is characterised by enhanced glycolytic flux for ATP production, glucose to lactate conversion and reduced mitochondrial oxidative phosphorylation, even under aerobic conditions (Chen et al, 2007). Although the underlying mechanisms for the prevalence of aerobic glycolysis in cancers remain complex, it is considered that tumour development within a hypoxic microenvironment, combined with mitochondrial defects in the electron transport chain, contribute to this metabolic phenotype (Gatenby and Gillies, 2004). Aerobic glycolysis may confer a survival benefit to cancer cells by: (1) facilitating tumour expansion and metastasis through the degradation of the extracellular matrix by secreted lactate, a by-product of glycolysis (Gatenby and Gillies, 2004), (2) supplying ATP to the tumour cells in low oxygen tissue environments with poor vascularisation (Cairns et al, 2011), and (3) apoptotic resistance through repressed

\footnotetext{
*Correspondence: Dr WY Sanchez; E-mail: w.sanchez1@uq.edu.au

${ }^{5}$ Current address: The University of Queensland, Therapeutics Research Centre, School of Medicine, Princess Alexandra Hospital, Woolloongabba, 4102, Queensland, Australia.

${ }^{6}$ Current address: The Bone Marrow Transplantation Laboratory, Queensland Institute of Medical Research, Herston 4006, Queensland, Australia.

${ }^{7}$ These authors contributed equally to this work.
} 
mitochondrial oxidative phosphorylation activity (Michelakis et al, 2008).

One of the key regulators of glycolysis and oxidative phosphorylation is the pyruvate dehydrogenase kinase (PDK). Under hypoxic conditions, hypoxia-inducible factor- $1 \alpha$ stabilizes and translocates into the nucleus to activate repressors of oxidative phosphorylation such as PDK. A combination of four PDK isoforms independently phosphorylates pyruvate dehydrogenase $(\mathrm{PDH})$, inhibiting the conversion of pyruvate to acetyl-CoA. This action shifts the burden of ATP production away from oxidative phosphorylation to glycolysis and alternative bioenergetic pathways (Michelakis et al, 2008).

Aerobic glycolysis has received substantial attention as a novel therapeutic target for cancer cells. Of the several glycolytic inhibitors currently being evaluated, emerging evidence suggests anti-tumour activity of dichloroacetate (DCA) against lung (Bonnet et al, 2007), breast (Sun et al, 2010), prostate (Cao et al, 2008), endometrial (Wong et al, 2008) and colorectal (Madhok et al, 2010) cancer cells. Dichloroacetate is an orally bioavailable, inexpensive small molecule and currently being evaluated in phase I/II clinical trials for glioblastoma, gliomas and other solid tumours (Yeluri et al, 2012). Dichloroacetate also appears to act synergistically with 5-fluourouracil in colorectal cancer cells (Tong et al, 2011), cisplatin in cervical cancer cells (Xie et al, 2010) and decitabine in breast and prostate cancer cells (Babu et al, 2011; Sun et al, 2011; Ayyanathan et al, 2012; Ishiguro et al, 2012). Conversely, other studies report that DCA was antagonistic towards the cytotoxicity of cisplatin and doxorubicin in some paediatric tumour cells (Heshe et al, 2011).

Dichloroacetate is a pyruvate mimetic that targets PDK, inhibiting the phosphorylation of $\mathrm{PDH}$. The phosphorylation of $\mathrm{PDH}$ is a rate-limiting factor for the oxidative metabolism of pyruvate entering the mitochondria (Kerr, 2010). As a result, DCA restores the activity of PDH and the supply of acetyl-CoA to the Krebs cycle and nicotinamide adenine dinucleotide (NADH) electron donation to the electron transport chain (Michelakis et al, 2008). An increase in electron transport chain activity is believed to cause the generation of mitochondrial reactive oxygen species (ROS), which is associated with mitochondrial transition pore opening, a loss of mitochondrial membrane potential $\left(\Delta \psi_{\mathrm{m}}\right)$ and ultimately apoptotic cell death (Bonnet et al, 2007).

Multiple myeloma (MM) is a haematological malignancy characterised by clonal proliferation of malignant plasma cells in bone marrow with a median survival of 3-5 years, one of the lowest of all cancers. The hemotherapeutic drug bortezomib induces profound apoptosis in myeloma cells, however, patients eventually die because malignant plasma cells become resistant to apoptosis. Resistance to apoptosis is linked to aerobic glycolysis and predicts a poor clinical outcome in cancer patients (Ziebart et al, 2010). In this study, we analysed whether myeloma cells demonstrate a metabolic phenotype characterised by glucose to lactate conversion and reduced oxidative capacity. We also examined the capacity of DCA to alter metabolic phenotype in MM cells and induce myeloma growth reduction.

\section{MATERIALS AND METHODS}

Cell cultures. RPMI8226 and U266 human myeloma cell lines were purchased from the American Type Culture Collection (Sydney, New South Wales, Australia). JJN-3, NCI-H929 and LP-1 human myeloma cell lines were obtained by a kind gift from Dr Andrew Hutchinson (University of Technology Sydney, New South Wale, Australia). RPMI8226-TGL human myeloma cell line was produced by the transduction of RPMI8226 cells with the NES-TGL construct, which expresses GFP and firefly
Luc (Ponomarev et al, 2004). Multiple myeloma cell lines were maintained at $37^{\circ} \mathrm{C}$ in a $5 \% \quad \mathrm{CO}_{2}$-humidified atmosphere in DMEM media supplemented with $4.5 \mathrm{gl}^{-1}$ D-glucose, $10 \%$ forward scatter (FCS), $100 \mathrm{U} \mathrm{ml}^{-1}$ penicillin, $100 \mathrm{mg} \mathrm{ml}^{-1}$ streptomycin, $2 \mathrm{~mm}$ L-glutamine, $1 \mathrm{~mm}$ sodium pyruvate and $10 \mathrm{~mm}$ HEPES.

Blood was obtained from healthy donors, with appropriate informed consent according to the Mater Adult Hospital Ethics Committee Guidelines. Peripheral blood mononuclear cells (PBMC) were isolated using Ficoll-Paque PLUS (GE Healthcare, Rydalmere, New South Wales, Australia) density gradient. Phorbol myristate acetate (PMA; Sigma-Aldrich, Sydney, New South Wales, Australia) was added to PBMC at the start of incubations with DCA at a dose of $10 \mathrm{ng} \mathrm{ml}^{-1}$. For all incubations with DCA (Sigma-Aldrich) or bortezomib (Janssen-Cilag Pty LTP, North Ryde, NSW, Australia), the MM cell lines and PBMC were incubated in RPMI media supplemented with 10\% FCS, $100 \mathrm{U} \mathrm{ml}^{-1}$ penicillin, $100 \mathrm{mg} \mathrm{ml}^{-1}$ streptomycin, $2 \mathrm{~mm}$ L-glutamine and $10 \mathrm{~mm}$ HEPES.

Measurements of Warburg effect. Myeloma cells $\left(5 \times 10^{4}\right.$ cells per $\mathrm{ml})$ and $\mathrm{PBMC}\left(5 \times 10^{5}\right.$ cells per $\left.\mathrm{ml}\right)$ were seeded in 24 -well plates with or without DCA for a 60 -h incubation. At the end of incubation, cell culture media was collected and analysed for lactate and glucose concentration (VITROS5600 Integrated System Mater Pathology, Brisbane, Queensland, Australia). The respiratory capacity and aerobic/anaerobic flux analyses of myeloma cells (RPMI8226-TGL, JJN-3 and U266), tumour cell lines (Hela, HepG2) and non-tumour cell lines (3T3-L1 fibroblasts, 3T3adipocytes, primary cardiac myocytes and $\mathrm{C} 2 \mathrm{C} 12$ myotubes) were performed via the Seahorse XF24 Extracellular Flux Analyser (Seahorse Bioscience, Billerica, MA, USA) as described previously (Chen et al, 2007; McGee et al, 2011). Myeloma cells were adhered to the bottom of the 24-well plate using Cell-Tak cell and tissue adhesive (BD Biosciences, Sydney, New South Wales, Australia). To control for the effect of cell viability on the respiratory capacity and aerobic/anaerobic flux analyses, plates were gently washed once with assay buffer immediately after each assay to remove dead cells, before the cell plate was frozen at $-80^{\circ} \mathrm{C}$. Plates were later thawed and cell counts performed using the CyQuant assay (Life Technologies, Mulgrave, Victoria, Australia), according to manufacturer's instructions.

Western blot analysis. Myeloma cells were seeded in triplicate wells and cultured without or with DCA for $24 \mathrm{~h}$. At the end of the culture, the cells were washed once with PBS before being spun down and resuspended in $100 \mu \mathrm{l}$ of $2 \%$ SDS lysis buffer $(50 \mathrm{~mm}$ Tris- $\mathrm{HCl} \mathrm{pH}$ 6.8, 20\% SDS, $10 \mathrm{~mm} \mathrm{NaF}$, activated $1 \mathrm{~mm} \mathrm{Na}_{3} \mathrm{VO}_{4}$ ). The cell lysate was placed in a water-bath sonicator on high for 5 min before being passed repeatedly through at 26 gauge syringe on ice. The protein concentration was measured using the NanoDrop spectrophotometer (Thermo Fisher Scientific, Wilmington, DE, USA) at an absorbance of $280 \mathrm{~nm}$, using lysis buffer as a blank control. Twenty-five microgram of total protein from each sample were resolved by electrophoresis on NuPAGE Novex 12\% Bis-Tris gels using MOPS-SDS running buffer (Life Technologies, Sydney, New South Wales, Australia). The proteins were transferred to Immobilon-P polyvinylidene fluoride membrane (Millipore, Billerica, MA, USA) for $15 \mathrm{~min}$ using the Pierce Fast semi-dry blotter according to the manufacturer's instructions (Pierce, Rockford, IL, USA). Following transfer, the PVDF membrane was washed with deionised water and incubated with Odyssey-blocking buffer (LI-CORE Biosciences, Lincoln, NE, USA) for $1 \mathrm{~h}$ at room temperature. The membrane was probed with primary antibody in Odyssey-blocking buffer for $1-2 \mathrm{~h}$ at room temperature or $4{ }^{\circ} \mathrm{C}$ overnight, washed in tris-buffered saline (TBS)-T and probed with secondary antibody in Odyssey blocking buffer for $1 \mathrm{~h}$ at room temperature. Primary antibodies included 
rabbit polyclonal anti-PDH-E1 $\alpha(1: 250)$, anti-phospho-PDH-E1 $\alpha$ (pSer293; 1:1000) and the loading control mouse monoclonal anti- $\beta$-actin $(1: 5000)$ (Life Technologies). Secondary antibody included goat anti-rabbit Alexa Fluor 680 and goat anti-mouse Alexa Fluor 488 antibodies $(1: 5000)$. The membrane was washed in TBS-T before visualisation via the Odyssey Infrared Imaging System (LI-CORE Biosciences).

Mitochondrial superoxide level and mitochondrial membrane potential $\left(\Delta \psi_{\mathrm{m}}\right)$ analysis. Mitochondrial superoxide levels were measured by staining MM cells cultured for $60 \mathrm{~h}$ without or with DCA with MitoSOX (5 $\mu \mathrm{m}$, Life Technologies), which is a mitochondrial targeted probe that fluoresces upon binding to free superoxide. As a positive control for mitochondrial superoxide levels, Antimycin A ( $50 \mu \mathrm{m}$; Sigma-Aldrich) was added to myeloma cells, for $30 \mathrm{~min}$ at $37^{\circ} \mathrm{C}$, causing a maximal increase in superoxide formation. Changes in $\Delta \psi_{\mathrm{m}}$ were measured after staining the cells with the cationic dye tetramethylrhodamine, ethyl ester (TMRE; $150 \mathrm{~nm}$, Life Technologies) that accumulates in the negatively charged inner-membrane of the mitochondria. As a positive control for loss of $\Delta \psi_{\mathrm{m}}$, carbonyl cyanide 4-(trifluoromethoxy) phenylhydrazone (FCCP; $5 \mu \mathrm{M}$; Sigma-Aldrich) was added to myeloma cells for $5 \mathrm{~min}$ at $37^{\circ} \mathrm{C}$, which caused immediate depolarisation of the mitochondrial membrane in live cells. To exclude MitoSOX or TMRE signals derived from dead cells arising during cultures, MitoSOX or TMRE signal were analysed in live cells gated on forward side (FCS) and side scatter (SSC) characteristics (FlowJo software, Ashland, OR, USA).

Annexin V, proliferation and cell cycle assay. To measure apoptosis and proliferation of myeloma cell lines and PBMC, the cells were cultured for $60 \mathrm{~h}$ as described above for measuring the Warburg effect. For apoptosis assay, cells were stained with annexin V (BD Biosciences) and 7-aminoactinomycin D (7-AAD; Sigma-Aldrich) and analysed by flow cytometry to determine the proportions of viable (annexin $\mathrm{V}^{-}$and $7-\mathrm{AAD}^{-}$), apoptotic (annexin $\mathrm{V}^{+}$and $7-\mathrm{AAD}^{+1-}$ ) and necrotic (annexin $\mathrm{V}^{-}$and 7-AAD ${ }^{+}$) cells. Proliferation was measured, after the addition of $37 \mathrm{bBq}\left[{ }^{3} \mathrm{H}\right]$ thymidine for the last $16 \mathrm{~h}$ of culture and expressed as the mean of quadruplicate counts per minute. For cell cycle assay, MM cell lines were incubated without or with $25 \mathrm{~mm}$ DCA for $24 \mathrm{~h}$ at $37^{\circ} \mathrm{C}$ and washed once with PBS. Ice cold $70 \%$ ethanol was then added to the cell pellets and incubated at $4{ }^{\circ} \mathrm{C}$ for $1 \mathrm{~h}$. The cells were then pelleted, washed with PBS, followed by addition of $50 \mu \mathrm{M}$ of RNase (100 $\mu \mathrm{g} \mathrm{ml}^{-1}$; Sigma-Aldrich) and incubated at $37^{\circ} \mathrm{C}$ for $15 \mathrm{~min}$. Following this, $200 \mu \mathrm{l}$ of 7 -AAD $\left(25 \mu \mathrm{g} \mathrm{ml}^{-1}\right)$ was added to the cell pellet for $5 \mathrm{~min}$ at $37^{\circ} \mathrm{C}$ before analysis by flow cytometry.

Myeloma-bearing mice. Myeloma-beraing mice were produced in-house according published protocol (Freeman et al, 2011). All experimental work involving animals was approved by the University of Queensland Animal Ethics Committees. Myelomabearing mice were divided into four cohorts: (1) control mice received daily intraperitoneal (i.p.) injections of PBS; (2) DCAtreated mice received daily i.p. injections of DCA $\left(200 \mathrm{mg} \mathrm{kg}^{-1}\right)$ and had free access to DCA-containing water $\left(0.7 \mathrm{gl}^{-1}\right)$; (3) bortezomib-treated mice received twice weekly i.p. injections of bortezomib $\left(0.5 \mathrm{mg} \mathrm{kg}^{-1}\right)$; (4) DCA + bortezomib-treated mice received both DCA and bortezomib at the doses described for cohort (2) and (3). The treatment regime began at 10 days after MM cell transplantation in mice with established myeloma as confirmed by serum lambda chain concentration (ELISA quantification kit, Bethyl Laboratories, Montgomery, TX, USA). Response to treatment was assessed by serum lambda chain concentration and survival of myeloma-bearing mice. Disease symptoms, which required that the myeloma-bearing mice be killed, included hunched posture, ruffled coat, weight loss, lethargy and hindlimb paralysis.
Statistical analysis. Statistical analysis was performed using GraphPad PRISM (Graphpad Software, San Diego, CA, USA). Data are presented as the mean \pm s.e.m. Statistical significance was calculated using a student's $t$-test, with a probability level of $P<0.05$ considered to be statistically significant. Statistical differences in the effect of DCA treatment at various concentrations was calculated using a one-way ANOVA with a post hoc Dunnett's test comparing the means to the untreated control. Logrank Mantel-Cox test was used to compare survival curves of treated and control myeloma-bearing mice. Kruskal-Wallis test was used to compare differences between DCA, bortezomib and $\mathrm{DCA}+$ bortezomib treatment, shown in Figure 5C, applying Bonferroni's adjustment for multiple comparisons in post hoc testing using Dunn's test.

\section{RESULTS}

Metabolic characterisation of MM cell lines. The metabolic features of six MM cell lines were compared during their growth under normoxic conditions within $60 \mathrm{~h}$ of culture. We also assessed the metabolic features of unstimulated-PBMC and PMA-stimulated PBMC that involve proliferating T cells (PMA-PBMC) within $60 \mathrm{~h}$ of culture. A difference in glucose utilisation and lactate production was observed between MM cell lines reflecting the heterogeneity in myeloma cell metabolism (Figure 1A). RPMI8226 $\left({ }^{* *} P<0.01\right)$, RPMI8226-TGL $\left({ }^{*} P<0.05\right)$ and JJN-3 $\left({ }^{* *} P<0.001\right)$ MM cell lines significantly increased the concentration of lactate in the cell culture medium compared with initial lactate concentration by producing $\sim 5.45,3.55$ and $4.98 \mathrm{~mm}$ of lactate, respectively. RPMI8226 and JJN3 MM cell lines significantly $\left({ }^{* *} P<0.01\right)$ reduced the concentration of glucose in the cell culture medium compared with initial glucose concentration, consuming $\sim 2.55$ and $1.85 \mathrm{~mm}$ of glucose, respectively. RPMI8226-TGL myeloma cells slightly reduced the concentration of glucose in the medium, whereas U226, NCI-H929 and LP-1 myeloma cells did not alter the levels of lactate and glucose in the medium (Figure 1A). Similarly, glucose and lactate levels remained unchanged in unstimulated-PBMC, whereas PMA-PBMC showed a significant increase in lactate production without decrease in glucose concentration. Lactate production by PMA-PBMC was significantly $\left({ }^{\star} P<0.05\right)$ lower than that by RPMI8226, RPMI8226-TGL and JJN-3 MM cell lines by, on average, 1.86-fold (Figure 1A), suggesting amplified aerobic glycolysis is in MM cell lines compared with healthy cells.

Our data suggest that $\sim 50 \%$ of examined MM cell lines ( 3 out of $6 \mathrm{MM}$ cell lines) use glycolysis as a bioenergetic pathway. We selected RPMI8226-TGL and JJN-3 myeloma cell lines displaying aerobic glycolysis as a representative Warburg MM cell line and U266, which displays no glucose to lactate conversion, as a representative non-Warburg MM cell line for subsequent experiments.

In cancers displaying the Warburg effect, aerobic glycolysis is typically associated with reduced oxygen consumption due to impaired oxidative phosphorylation capacity in mitochondria (Gatenby and Gillies, 2004; Wu et al, 2007). Therefore, we examined whether representative Warburg and non-Warburg MM cell lines displayed differences in oxidative capacity and aerobic/ anaerobic flux using extracellular flux analysis (Figure 1B and C). Interestingly, all MM cell lines irrespective of aerobic glycolysis showed a low maximal respiratory capacity after stimulation with FCCP, on average 3.12-fold lower than non-myeloma Hela and HepG2 tumour cell lines, and 24.3-fold lower than non-tumour cell lines (Figure 1B). Representative Warburg-MM cell lines (RPMI8226-TGL, JJN3) had the lowest aerobic/anaerobic ratio of all the cell lines examined (Figure 1C). 
A
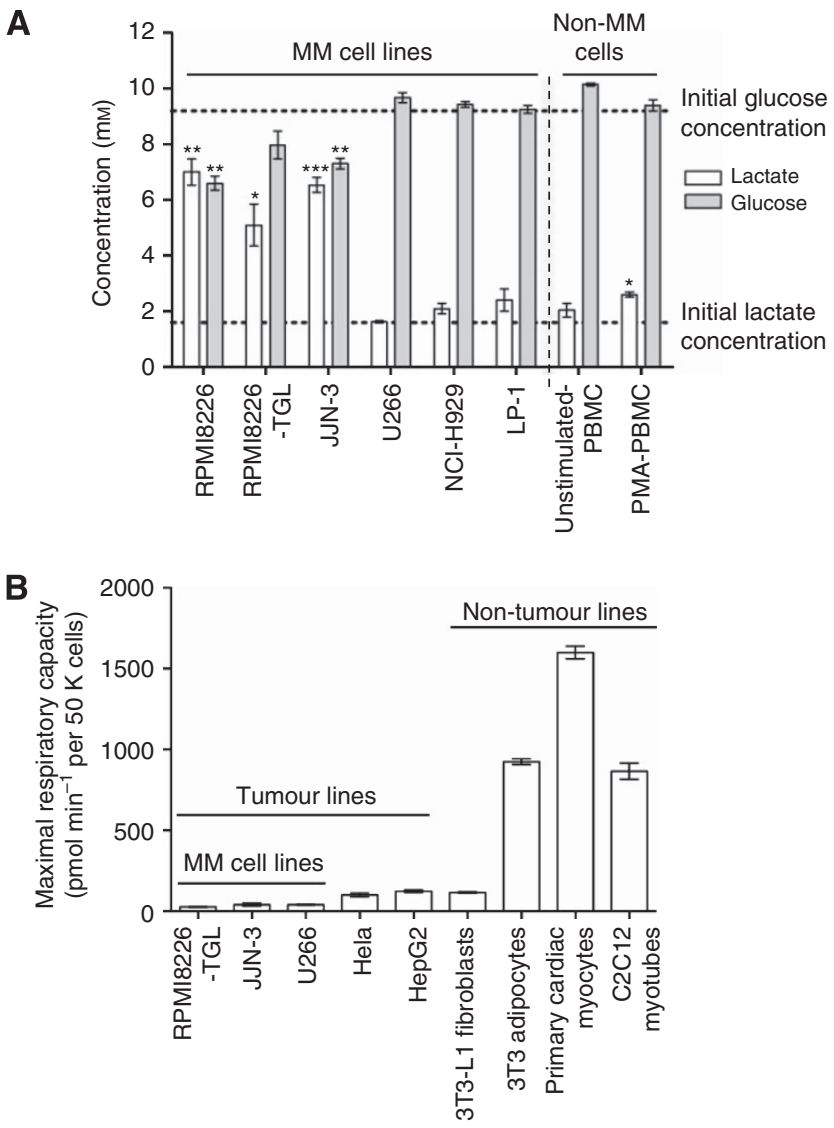

C

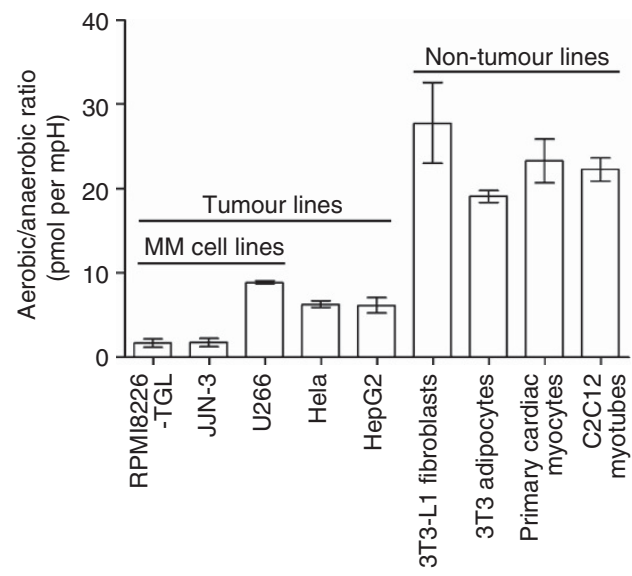

Figure 1. Metabolic features of MM cell lines. (A) Normalised glucose and lactate concentration by MM cell lines (RPMI8226, RPMI8226-TGL, JJN3, U226, NCl-H929, LP-1), unstimulated-PBMC and PMA-

stimulated PBMC (PMA-PBMC) within $60 \mathrm{~h}$ of culture under normoxic culture conditions. Data shown are the mean concentration from 3-4 independent experiments ( \pm s.e.m.; ${ }^{\star} P<0.05$, ${ }^{\star \star} P<0.01$, ${ }^{\star \star \star} P<0.001$ ). (B) Maximal respiratory capacity (oxygen consumption rate following treatment with FCCP) and (C) aerobic/anaerobic ratio (oxygen consumption rate (OCR)/extracellular acidification rate (ECAR)) of MM cell lines (RPMI8226-TGL, JJN3 and U226), non-myeloma cell lines (Hela, HepG2) and non-tumour cell lines (3T3-L1 fibroblasts, 3T3 adipocytes, primary cardiac myocytes, C2C12 myotubes). Data shown are representative of 2-3 independent experiments (mean \pm s.e.m.).

Dichloroacetate inhibited glycolysis, enhanced respiration and activated the PDH complex in MM cell lines. As DCA inhibits aerobic glycolysis in lung cancer cell lines (Bonnet et al. 2007; Stockwin et al, 2010; Cairns et al, 2011), stimulating a shift towards oxidative phosphorylation, we tested the effectiveness of DCA to induce these changes in MM cell lines. Dichloroacetate treatment $(5 \mathrm{mM})$ to RPMI8226-TGL MM cells resulted in a significantly lower $\left({ }^{\star} P<0.05\right) \quad$ concentration of lactate $(3.23 \pm 0.41 \mathrm{~mm})$ in the conditioned media compared with the untreated control $(5.1 \pm 0.76 \mathrm{mM})$. Similarly, DCA treatment $(10 \mathrm{mM})$ to JJN-3 MM cells saw a significantly lower $\left({ }^{* * P}<0.01\right)$ concentration of lactate $(3.53 \pm 0.78 \mathrm{~mm})$ compared with the untreated control $(6.53 \pm 0.27 \mathrm{mM})$. For both RPMI8226-TGL and JJN-3 MM cell lines, lactate levels in the conditioned media continued to be lower with increasing concentration of DCA treatment (Figure 2A).

Dichloroacetate ( $15 \mathrm{~mm}$ ) treatment of RPMI8226-TGL MM cells resulted in significantly higher $\left({ }^{\star} P<0.05\right)$ glucose concentration $(9.23 \pm 0.23 \mathrm{~mm})$ in the conditioned media compared with the untreated control $(7.97 \pm 0.5 \mathrm{mM})$. In JJN-3 MM cells, DCA treatment $(10 \mathrm{~mm})$ also resulted in significantly higher $\left({ }^{*} P<0.05\right)$ glucose levels $(8.47 \pm 0.36 \mathrm{~mm})$ in conditioned media compared with the untreated control $(7.3 \pm 0.19 \mathrm{~mm})$. In contrast, lactate and glucose levels in the conditioned media of the non-Warburg MM cell line, U226, was not affected by DCA treatment (Figure 2A, B).

Dichloroacetate at concentration of $>5 \mathrm{~mm}$ had no effect on lactate levels in unstimulated-PBMC conditioned media, but the glucose concentration $(9.45 \pm 0.05 \mathrm{~mm})$ was significantly lower $\left({ }^{*} P<0.01\right)$ compared with the untreated control $(10.15 \pm$ $0.05 \mathrm{~mm}$ ) (Figure 2B). Dichloroacetate treatment $(>15 \mathrm{~mm})$ of PMA-stimulated PBMCs resulted in significantly lower $\left({ }^{*} P<0.05\right)$ lactate levels $(2.05 \pm 0.15 \mathrm{~mm})$ in the conditioned media compared with the untreated control $(2.9 \pm 0.2 \mathrm{~mm})$, with no change observed in glucose (Figure 2A and $\mathrm{B}$ ).

Concurrent with changes in lactate production and glucose concentration, DCA treatment significantly increased $\left({ }^{\star} P<0.05\right)$ the oxygen consumption rate of representative Warburg-MM cell lines (RPMI8226-TGL, JJN3) and had no effect on a representative non-Warburg MM cell line U226 (Figure 2C).

The inhibition of aerobic glycolysis by DCA occurs via the inhibition of PDK (Bonnet et al, 2007; Michelakis et al, 2008; Madhok et al, 2010), a kinase that phosphorylates and inhibits $\mathrm{PDH}$ within the mitochondria. We assessed whether the decreased production of lactate and increased respiratory rate induced by DCA treatment in MM cells involved activation of the $\mathrm{PDH}$ complex as measured by the dephosphorylation of PDH-E1 $\alpha$ (Figure 2D). Activation of the PDH complex should take place shortly after DCA gains access to the cells, therefore, the time points used for these analyses were $24 \mathrm{~h}$ (Figure 2D). Immunoblotting for $\mathrm{PDH}-\mathrm{E} 1 \alpha\left(\mathrm{pSer}^{293}\right)$ showed that DCA treatment reduced PDH-E1 $\alpha\left(\right.$ pSer $\left.^{293}\right)$ phosphorylation in RPMI8226-TGL, JJN3 and U226 MM cell lines (Figure 2D). This DCA treatment did not affect expression levels of PDH-E1 $\alpha$ and the housekeeping protein $\beta$-actin in RPMI8226-TGL, JJN3 and U226 MM cell lines (Figure 2D). Together, these data demonstrate that DCA causes the dephosphorylation of PDH-E1 $\alpha$ consistent with the reported mechanism of DCA action (Bonnet et al, 2007; Michelakis et al, 2008; Madhok et al, 2010) but this is not correlated with aerobic glycolysis in MM cell lines.

Dichloroacetate increased superoxide production without a reduction in the $\Delta \psi_{\mathrm{m}}$ in $\mathbf{M M}$ cell lines. Dichloroacetate treatment leads to increased ROS formation including superoxide production in various cancers, which is attributed to greater oxidative phosphorylation activity and/or potentially due to greater substrate entry into the mitochondria (Bonnet et al, 2007; Michelakis et al, 2008; 2010; Stockwin et al, 2010). On the basis of the observed DCA-mediated increase in respiratory capacity in MM cells and oxygen consumption (Figure 2C), we asked whether DCA treatment in MM cells leads to increased mitochondrial superoxide production. Antimycin A stimulation increased mitochondrial superoxide production in RPMI8226-TGL, JJN-3 and U226 cells compared with untreated cells (Figure 3A). 
A

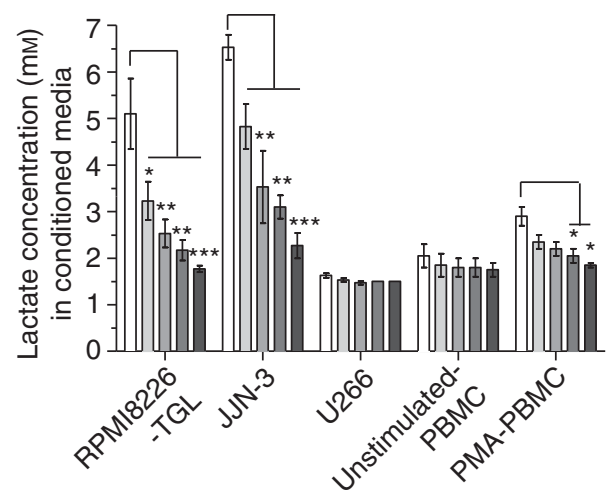

B

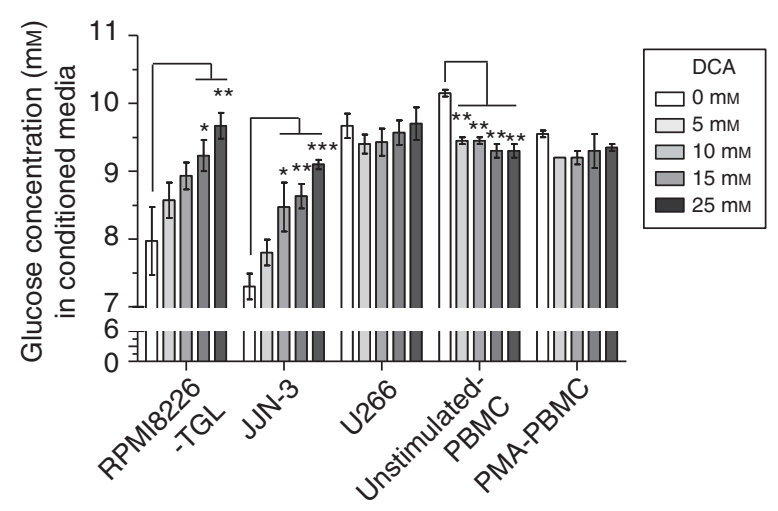

C

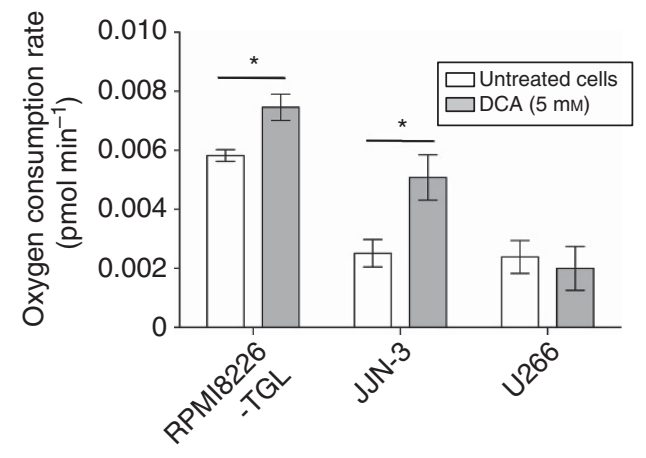

D

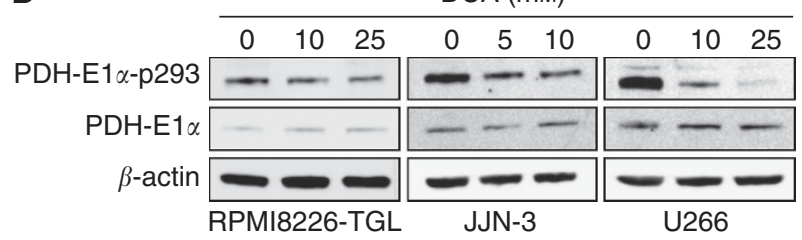

Figure 2. Effect of DCA on glycolysis, oxygen consumption and PDH complex in MM cell lines. (A, B) Lactate and glucose concentration in the conditioned media from MM cell lines (RPMI8226-TGL, JJN3, U226), unstimulated-PBMC and PMA-PBMC in the absence or presence of DCA $(1.25-25 \mathrm{~mm})$ within $60 \mathrm{~h}$ of culture under normoxic culture conditions. (C) Oxygen consumption rate of MM cell lines (RPMI8226-TGL, JJN-3 and U266) in the absence or presence of $5 \mathrm{~mm}$ DCA. Data shown are representative of 3-8 independent experiments (mean \pm s.e.m., ${ }^{*} P<0.05$ ). (D) Western blot analysis of PDH-E1 $\alpha-p 293$, PDH-E1 $\alpha$ and $\beta$-actin from RPMI8226-TGL, JJN-3 and U266 MM cell lines cultured without or with DCA (5, 10 and $25 \mathrm{~mm})$ for $24 \mathrm{~h}$. Data shown are representative of three independent experiments.

Dichloroacetate at concentration of $10 \mathrm{~mm}$ increased superoxide production in JJN-3 cells, while a higher DCA concentration of $25 \mathrm{~mm}$ was required to increase superoxide production in RPMI8226-TGL cells (Figure 3A). Dichloroacetate doses of 10 or
$25 \mathrm{~mm}$ failed to induce convincing changes in superoxide production in U266 cells (Figure 3A). These data suggest that DCA increases superoxide production exclusively in Warburg-MM cell lines.

Dichloroacetate treatment in cancer cells, along with the stimulation of superoxide production, induces the reduction of $\Delta \psi_{\mathrm{m}}$, which initiates apoptosis and cancer cell death (Michelakis et al, 2008; Sun et al, 2010). As shown in Figure 3B, FCCP caused mitochondrial depolarisation in all MM cells compared with untreated cells. However, DCA treatment failed to reduce $\Delta \psi_{\mathrm{m}}$ in any tested MM cell lines, moreover, DCA at doses of 10 and $25 \mathrm{~mm}$ tended to increase the $\Delta \psi_{\mathrm{m}}$ in RPMI8226-TGL cells (Figure 3B). Our results suggest that there is no association with DCA-mediated increases in superoxide production and the reduction of $\Delta \psi_{\mathrm{m}}$ in MM cell lines.

Dichloroacetate induced apoptosis and inhibited the proliferation of MM cell lines. As DCA-mediated increases in superoxide production can lead to apoptosis (Cao et al, 2008; Michelakis et al, 2008), we analysed whether DCA treatment induced apoptosis in MM cells, reflected by reduced numbers of viable (non-apoptotic/ non-necrotic) cells. We also assessed whether DCA is able to induce apoptosis of unstimulated-PBMC and PMA-PBMC. The proportions of viable RPMI8226-TGL, JJN-3 and U226 cells significantly decreased $\left({ }^{*} P<0.05\right)$, albeit to varying degrees, as DCA concentrations increased (Figure 4A). Dichloroacetate at concentration of $>5 \mathrm{~mm}$ reduced the proportion of viable JJN-3 cells, relative to untreated cells, while concentrations $>15 \mathrm{~mm}$ were required for the same effect in RPMI8226-TGL and U226 cells (Figure 4A). Dichloroacetate at doses of 5-15 mm did not alter the proportion of viable unstimulated-PBMC and PMA-PBMC. Higher concentration of DCA $(>25 \mathrm{~mm})$ significantly reduced $\left({ }^{*} P<0.05\right)$ the proportion of viable unstimulated-PBMC and marginally affected the proportion of viable PMA-PBMC relative to untreated cells (Figure 4A). These data suggest that a window for selective DCA-mediated apoptosis in MM cells exists.

In addition to the induction of apoptosis reflected by a reduction in cell viability, a major action associated with DCA treatment is the inhibition of proliferation in various cancer cells (Bonnet et al, 2007; Cao et al, 2008; Wong et al, 2008; Sun et al, 2010). Therefore, we investigated the effect of DCA on the proliferation of MM cell lines. Dichloroacetate treatment significantly inhibited $\left({ }^{*} P<0.05\right)$ cell proliferation in a dosedependent manner in RPMI8226-TGL, JJN3 and U226 cells, albeit to various degrees (Figure 4B). The $\mathrm{IC}_{50}$ of DCA-induced inhibition of cell proliferation in RPMI8226-TGL, JJN3 and U226 cells were $\sim 20.48,11.78$ and $15.92 \mathrm{~mm}$, respectively (Figure 4B). We also chose to measure the effect of DCA on MM cell cycle after a 24-h of incubation, in time frames of reduced effect of DCA on cell, rather than $60 \mathrm{~h}$, a typical time points used for analysis of DCA effect on proliferation and cell viability (Figure $4 \mathrm{~A}$ and $\mathrm{B}$ ). The presence of DCA caused a significant $\left({ }^{\star} P<0.05\right) \mathrm{G}_{0 / 1}$ phase arrest in RPMI8226-TGL and U266 cells, and a $\mathrm{G}_{2} \mathrm{M}$ phase arrest in JJN-3 cells (Figure $4 \mathrm{C}$ ).

Dichloroacetate increased the sensitivity of MM cell lines to the chemotherapeutic drug bortezomib. Our in vitro data suggest that DCA inhibited aerobic glycolysis, increased superoxide production (Figure 3A), induced apoptosis and suppressed cell proliferation (Figure 4A and B), which can all lead to myeloma suppression. On the basis of these in vitro data, we decided to assess whether DCA can prolong survival and suppress myeloma growth in myeloma-bearing mice developed by transplantation of the Warburg-MM cell lines, lambda-secreting RPMI8226-TGL MM cell line, into immune-compromised NOD/SCID mice (Freeman et al, 2011). We also assessed whether DCA can be used to complement bortezomib, a clinically used anti-myeloma therapy. Each treatment, DCA (i.p. $200 \mathrm{mg} \mathrm{kg}^{-1}$ per day 

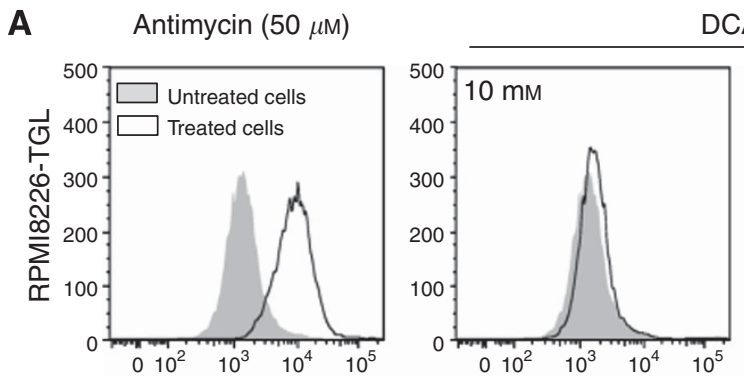

$\mathrm{DCA}(\mathrm{mm})$
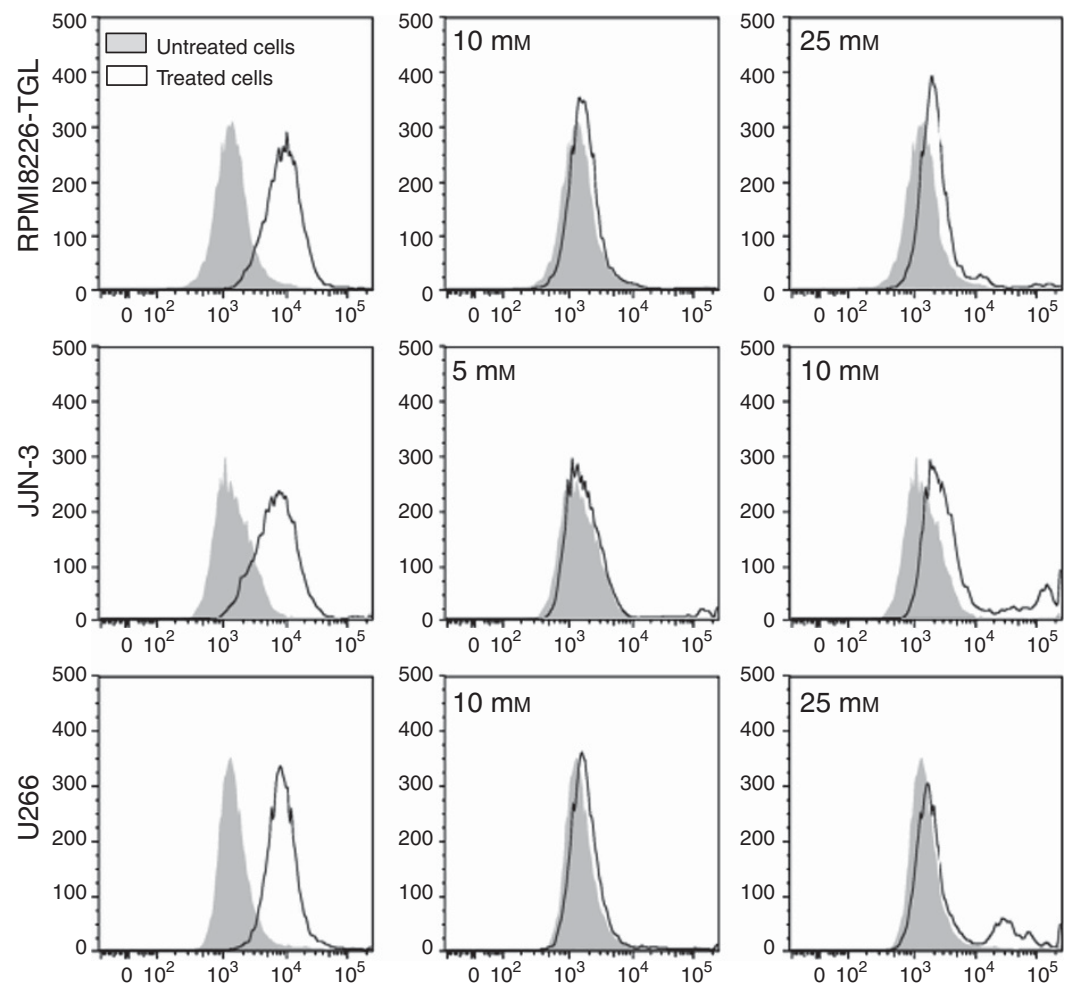

B

$\operatorname{FCCP}(5 \mu \mathrm{M})$
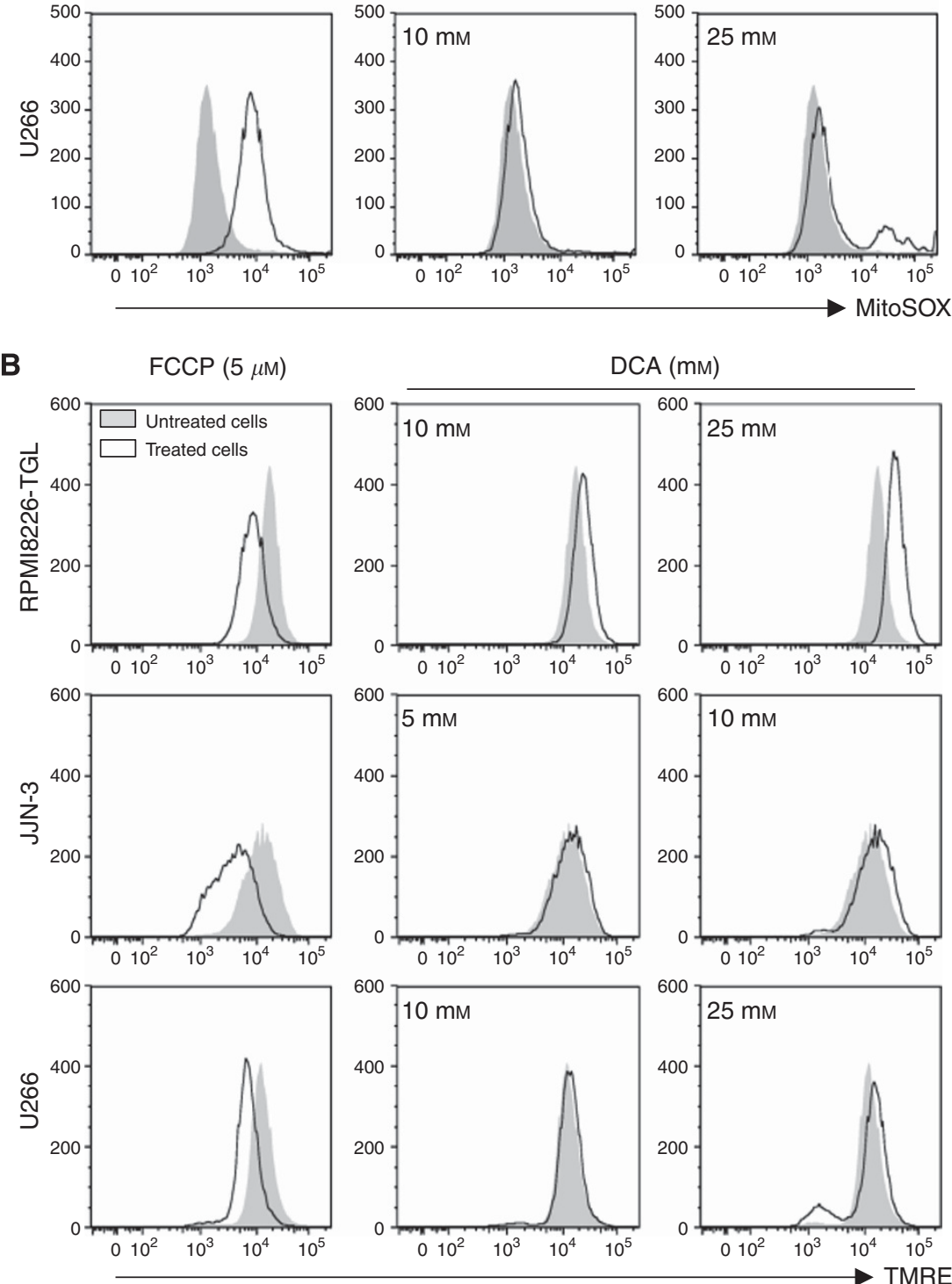

Figure 3. Dichloroacetate treatment increases superoxide formation without reduction in the $\Delta \psi_{\mathrm{m}}$ in $\mathrm{MM}$ cell lines. Myeloma cells $\left(5 \times 10^{4}\right.$ cells per $\mathrm{ml}$ ) were cultured without or with DCA $(5,10,25 \mathrm{~mm}$ ) for $60 \mathrm{~h}$. (A) To measure superoxide formation, fresh MM cell lines treated with Antimycin A $(50 \mu \mathrm{M})$ or MM cell lines cultured without or with DCA were stained with MitoSOX ( $5 \mu \mathrm{M})$ and analysed by flow cytometry. (B) To measure changes in the $\Delta \psi_{\mathrm{m}}$, fresh MM cell lines treated with FCCP $(5 \mu \mathrm{M})$ or MM cell lines cultured without or with DCA were stained with TMRE (150 nM) and analysed by flow cytometry. Representative histograms of MitoSOX and mitochondrial TMRE fluorescence from one of three independent experiments are shown. 

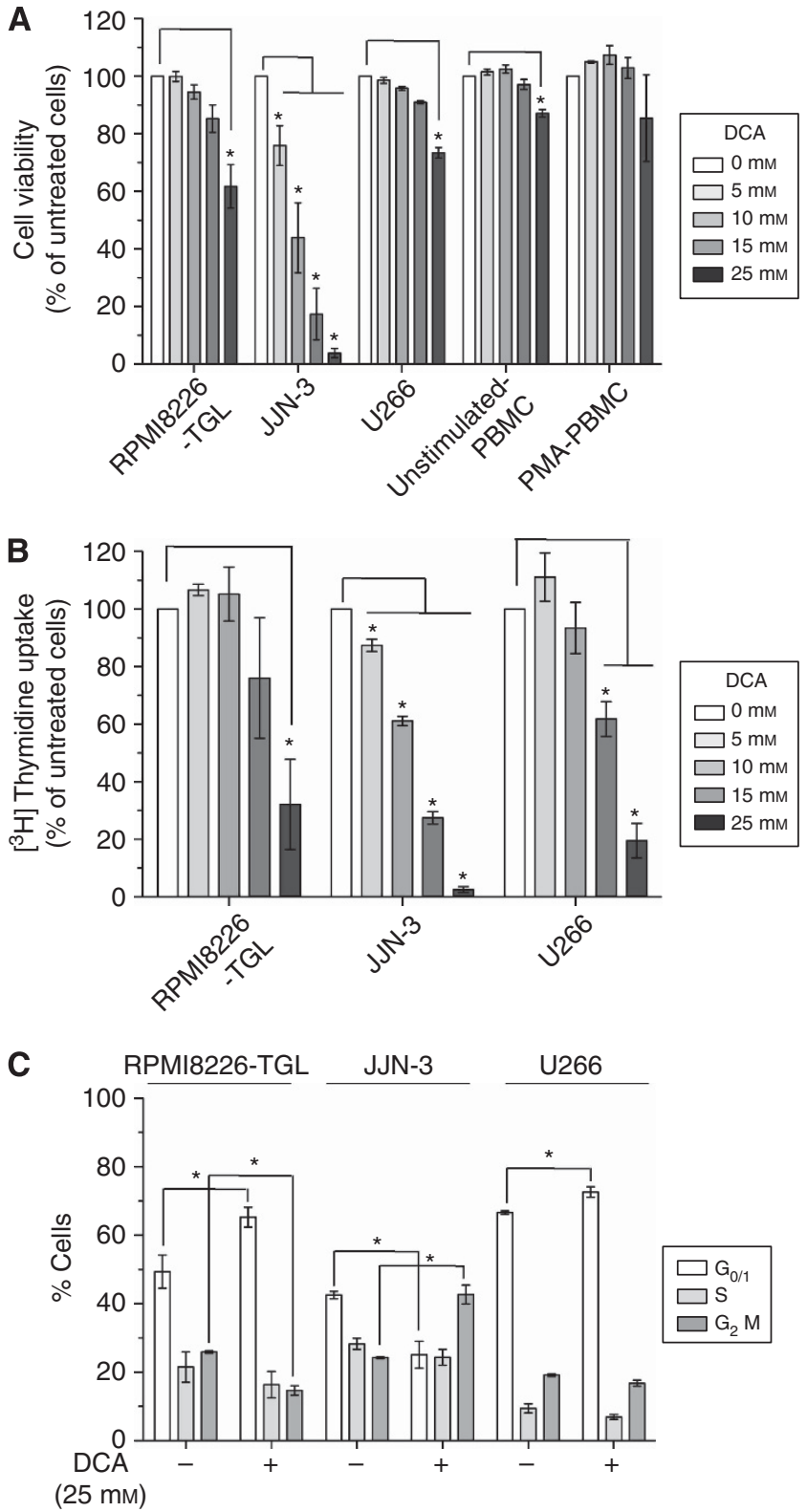

Figure 4. Dichloroacetate induces apoptosis and inhibits proliferation in $\mathrm{MM}$ cell lines. Myeloma cell lines $\left(5 \times 10^{4}\right.$ cells per $\left.\mathrm{ml}\right)$, unstimulatedPBMC and PMA-PBMC $\left(5 \times 10^{5}\right.$ cells per $\left.\mathrm{ml}\right)$ harvested after $60 \mathrm{~h}$ of culture without or with DCA (1.25-25 mM) and analysed for apoptosis and cell proliferation. (A) Apoptotic cells were assessed by AnnexinV and $7 A A D$ staining and defined as $A n n e x i n V^{+} 7 A A D^{+/-}$events, whereas viable cells defined as Annexin $V^{-} 7 A^{-} A^{-}$events. Data show the proportion of viable Annexin $V^{-} 7 A A D^{-}$cells (mean \pm s.e.m., ${ }^{\star} P<0.05$ ) and representative of three independent experiments. (B) Proliferation of MM cell lines was analysed by measuring the uptake of $\left[\mathrm{H}^{3}\right]$ thymidine during the final $16 \mathrm{~h}$ of culture. Data shown are representative of three experiments (mean \pm s.e.m., ${ }^{\star} P<0.05$ ). (C) Multiple myeloma cell lines $\left(5 \times 10^{5}\right.$ cells per $\left.\mathrm{ml}\right)$ cultured without or with DCA $(25 \mathrm{~mm})$ harvested after $24 \mathrm{~h}$ and analysed for cell cycle by flow cytomery. Data show the proportion of cells in $\mathrm{G}_{0 / 1}, \mathrm{~S}$ and $\mathrm{G}_{2} \mathrm{M}$ phase of cell cycle and representative of three independent experiments (mean \pm s.e.m., ${ }^{\star} P<0.05$ ).

in addition to oral DCA in drinking water) or bortezomib (i.p. $0.5 \mathrm{mg} \mathrm{kg}^{-1}$ twice weekly) administered alone did not improve survival of myeloma-bearing mice compared with control mice (overall survival: DCA-treated mice 22 days, bortezomib-
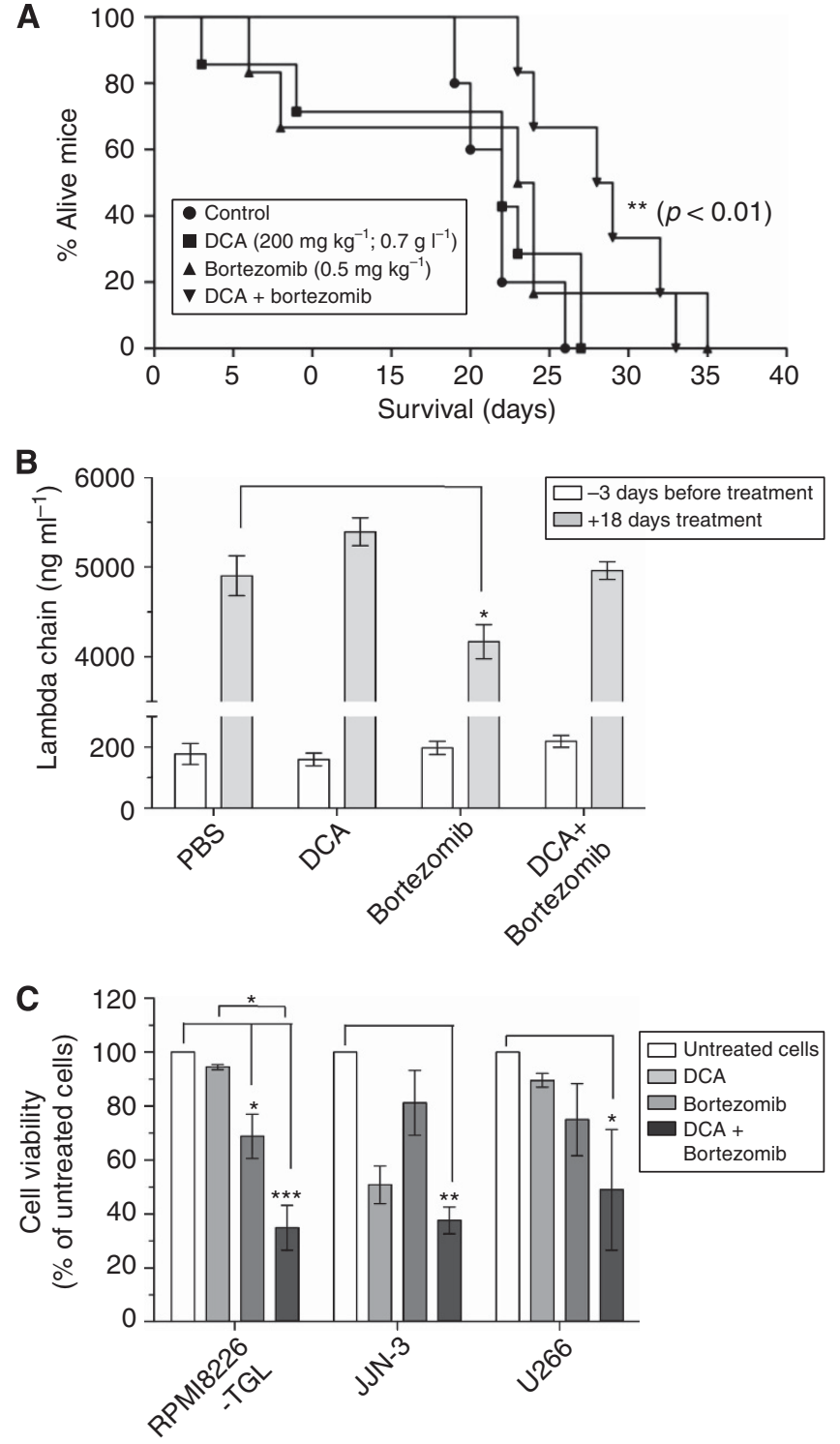

Figure 5. Testing efficiency of DCA treatment in myeloma-bearing mice. (A) Kaplan-Meier plots showing survival of four different cohorts of myeloma-bearing mice treated simultaneously with vehicle $(n=5)$, DCA (daily i.p. $200 \mathrm{mg} \mathrm{kg}^{-1}$, orally in drinking water $0.7 \mathrm{gl}^{-1} ; n=7$ ), bortezomib (twice weekly i.p. $0.5 \mathrm{mg} \mathrm{kg}^{-1} ; n=6$ ) or DCA + bortezomib $(n=6)$, over a period of 35 days after commencing of treatment (DCA + bortezomib treated mice vs control group, ${ }^{\star *} P<0.01$ ). (B) Serum lambda concentration in control, DCA, bortezomib and DCA + bortezomib treated mice at -3 days and +18 days of treatment commencement (mean \pm s.e.m., 5-7 mice per group; $\left.{ }^{\star} P<0.05\right)$. (C) Myeloma $\left(5 \times 10^{4}\right.$ cells per $\left.\mathrm{ml}\right)$ cell lines cultured without or with DCA (10 mM), bortezomib (RPMI8226-TGL: $5 \mathrm{nM}, \mathrm{JJN}-3$ and U266: $10 \mathrm{~nm}$ ) and DCA + bortezomib harvested after $60 \mathrm{~h}$ of culture and analysed for apoptosis. Apoptotic cells were assessed by AnnexinV and 7AAD staining and defined as AnnexinV $V^{+} 7 A A D^{+/-}$events, whereas viable cells defined as Annexin $V^{-} 7 A A^{-}$events. Data show the proportion of viable Annexin $V^{-} 7 A^{-} D^{-}$cells (mean \pm s.e.m., ${ }^{\star} P<0.05,{ }^{\star \star} P<0.01,{ }^{\star \star *} P<0.001$ ) and representative of three-four independent experiments.

treated mice 23.5 days, control mice 22 days; Figure 5A). However, DCA administered in combination with bortezomib significantly prolonged $\left({ }^{* *} P<0.01\right)$ the survival of myeloma-bearing mice compared with control mice (overall survival: DCA + bortezomib- 
treated mice 28.5 days $v s$ control mice 22 days; Figure 5A). After 18 days of treatment, neither DCA alone or DCA + bortezomib treatment affected serum lambda concentration compared with that in control mice (Figure 5B). However, bortezomib administered alone significantly reduced $\left({ }^{\star} P<0.05\right)$ serum lambda concentration compared with that of control mice (Figure $5 \mathrm{~B}$ ).

On the basis of the prolonged survival of myeloma-bearing mice that received DCA + bortezomib treatment, we asked whether DCA combined with bortezomib facilitated apoptosis and thus reduced the viability of MM cell lines. Even low DCA concentrations of $10 \mathrm{~mm}$ combined with bortezomib (10 nM) significantly decreased $\left({ }^{* * *} P<0.001\right)$ the proportion of viable RPMI8226-TGL MM cells compared with that induced by DCA or bortezomib alone (Figure 5C). There was also a significant decrease in the proportion of viable JJN-3 $\left({ }^{* *} P<0.01\right)$ and U226 $\left({ }^{*} P<0.05\right)$ cells by combined DCA and bortezomib treatment (DCA $10 \mathrm{~mm}$, Bortezomib $5 \mathrm{~nm}$ ), compared with untreated cells (Figure 5C).

\section{DISCUSSION}

This study revealed three key findings: (i) metabolic remodelling typical of the Warburg effect with increased lactate production and decreased oxidative capacity occurs in approximately half of the examined MM cell lines, (ii) DCA shifts metabolism in MM cell lines away from lactate and toward oxidative phosphorylation and this shift is associated with increased superoxide production, apoptosis and suppression of cell proliferation and (iii) DCA increased MM cell line sensitivity to the bortezomib and when administered with bortezomib improved the survival of myelomabearing mice.

Given that MM cells preferentially grow in the hypoxic bone marrow environment and that the Warburg effect confers greater advantage under hypoxic conditions, we expected that a Warburg effect may not be active in MM cell lines growing under normoxic conditions. It was rather surprising that under normoxic conditions as many as $50 \%$ of MM cell lines can be defined as Warburg MM cell lines, based on lactate and glucose levels in cell culture conditioned medium, and reduced oxidative capacity. Elevated lactate in the media, above the initial concentration, indicates lactate production as a result of glycolytic activity. Similarly, a reduction in glucose in the media suggests the activity of glucoseconsuming pathways, including glycolysis. In comparison with healthy PMA-PBMC, which show an appreciable Warburg effect, lactate production was by, on average, 1.86-fold higher in Warburg MM cell lines. The apparent absence of lactate production and glucose consumption by non-Warburg MM cell lines suggests that either the Warburg effect is not active under normoxic conditions or that non-glucose bioenergetic pathways involving oxidative phosphorylation are functional in these MM cell lines. These results are in line with a previous study, which described that isolated peripheral blood plasma cells from a myeloma patient use both glycolysis and oxidative phosphorylation for energy production (Stjernholm, 1967; Yeluri et al, 2012).

Metabolic heterogeneity observed in MM cell lines is similar to that reported in leukaemic cell lines, which use glycolysis but also non-glucose bioenergetic pathways such as fatty acid oxidation and/or amino-acid metabolism (Suganuma et al, 2010; Tong et al, 2011). Our demonstration that $50 \%$ of MM cells display the Warburg effect raises the possibility that the Warburg effect could contribute to MM progression in a large number of patients and identifies drugs that aim to reverse the Warburg effect as potential therapies to combat myeloma disease.

We demonstrated that MM cell lines exhibited extremely lowrespiratory capacity compared with other tumour and non-tumour cells lines, raising the possibility of silenced oxidative phosphorylation in myeloma cells. It has been proposed that silenced oxidative phosphorylation and the upregulation of glycolysis may confer a survival advantage by preventing the chronic accumulation of superoxide (Jones and Thompson, 2009; Gogvadze et al, 2010; Xie et al, 2010). Alternatively, silenced oxidative phosphorylation may confer a growth advantage by shifting carbon units to biosynthetic pathways rather than ATP generation, which is maintained by glycolysis.

We demonstrated that DCA treatment reduced lactate production in Warburg MM cell lines, suggesting that DCA may have an active role in reversing the Warburg effect in MM cells. A reduction in lactate in cell culture medium was achieved with the lowest tested DCA concentration of $5 \mathrm{~mm}$, which did not induce apoptosis or suppress proliferation in myeloma cells. During our analysis of lactate production, we uncovered evidence that DCA profoundly reduced glucose concentration in the media of Warburg MM cell lines. It is not clear how DCA regulates glucose consumption by myeloma cells. However, other studies suggest that reducing glucose consumption, by decreasing MM glucose transporter expression in myeloma cells, by the anti-myeloma agent 8-aminoadenosine, can initiate apoptosis (Ghias et al, 2005; Shanmugam et al, 2009; Babu et al, 2011). Further research will be required to determine whether DCA regulates glucose transporters in myeloma cells exhibiting the Warburg effect.

The role of DCA in increasing oxygen consumption is thought to be through the inhibition of PDK and activation of the PDH complex (Michelakis et al, 2008; Heshe et al, 2011). This is well appreciated in lung and colorectal cancer cells (Bonnet et al, 2007; Cairns et al, 2009; Kerr, 2010; Seth et al, 2011). In this study, we provided evidence that DCA activated the PDH complex evidenced by dephosphorylation of the PDH-E1 $\alpha$-pSer293 in both Warburg MM cells (e.g., RPMI8226-TGL, JJN-3) and in non-Warburg MM cells (e.g., U226). Also, DCA-mediated activation of the PDH complex seen in Warburg MM cell lines is associated with increased oxygen consumption. Interestingly, dephosphorylation of the PDH-E1 $\alpha-\mathrm{pSer}^{293}$ subunit in U266 myeloma cell line occurred without the increase in oxygen consumption (Figure 2D). This suggests that dephosphorylation of PDH-E1 $\alpha$-pSer292 may be a poor predictor for oxygen consumption and gives rise to the possibility that changes in the phosphorylation of other sites on the $\mathrm{PDH}$ complex may better predict changes in oxygen consumption between different myeloma cell lines. However, currently antibodies for the two other phosphorylation sites on PDH-E1 $\alpha$ (that is, Ser232 and Ser300) were not commercially available limiting further progress in this research area.

We demonstrated that the DCA-mediated increase in respiration capacity was associated with increased ROS production (Figure 3). Other studies suggest that DCA-induced ROS formation in turn activates apoptosis and affects proliferation of cancer cells (Michelakis et al, 2008). Our results presented here generally agree with previous reports regarding the importance of DCA in inducing ROS, and now provide clear evidence that only DCA concentrations that induce ROS formation have apoptotic and anti-proliferative effect on myeloma cells. Lower DCA concentrations that suppressed lactate production, increased oxidative capacity and activated PDH complex were not able to induce a robust apoptotic response or suppress proliferation of MM cell lines. It seems that DCA-driven metabolic changes in MM cell lines exhibiting the Warburg effect may not cause apoptosis unless they occurring in the context of robust ROS formation. It appeared that the rate of ROS formation, combined with reduced lactate, make JJN-3 MM cells more sensitive and RPMI8226-TGL and U226 MM cells less sensitive to the pro-apoptotic and anti-proliferative effect of DCA. In addition, the presence of DCA arrested JJN-3 cells at a different part of the cell cycle $\left(\mathrm{G}_{2} \mathrm{M}\right.$ phase) compared with the other myeloma cell line $\left(\mathrm{G}_{0 / 1}\right.$ phase). Previous 
studies suggest similar effect of DCA on colorectal cancer cell lines (Cao et al, 2008; Wong et al, 2008; Madhok et al, 2010).

As with several other studies, we demonstrate that relatively high concentrations of DCA (approximately >5-10 mM) are required to alter metabolic activity, increase ROS formation, induce apoptosis and inhibit myeloma cell proliferation in vitro. These effects are believed to be a result of PDK inhibition by DCA (Michelakis et al, 2008). However, the concentrations of DCA required to induce the desired anti-cancer effect (metabolic or on cell viability) are several times greater than the inhibition constant $\left(K_{\mathrm{i}}\right)$ of PDK1-4. For example, the $K_{\mathrm{i}}$ of PDK1, 2 and 4 range between $0.2-1.0 \mathrm{~mm}$, while the $K_{\mathrm{i}}$ of PDK3 is $\sim 8 \mathrm{~mm}$ (Ammini and Stacpoole, 2003). It is unlikely that DCA is targeting PDK3 in MM owing to its limited expression in the testis, kidney and brain (Sugden and Holness, 2003). In contrast, the more DCA-sensitive PDK2 is ubiquitously expressed throughout the body and may be target in MM. This suggests that in MM, the anti-cancer effects observed in the presence of DCA cannot be solely attributed to PDK inhibition. In addition to the direct effects of DCA on PDK inhibition, many changes in gene and protein expression could occurred in these time frames as the cells adapt to the presence of DCA over time.

A previous study demonstrated that DCA treatment induces a number of proteomic changes in several cancer cell lines and tumours related to cellular metabolism, proliferation and mitochondrial dysfunction (Stockwin et al, 2010). Elevated ROS levels within MM cell lines after DCA treatment may also be due to these genomic or proteomic changes related to cellular metabolism rather than due to solely PDK inhibition. Other studies suggested that cells undergoing 'metabolic crisis', due to a defect in electron transport chain complex IV, were more sensitive to DCA treatment as alternate metabolic pathways were unavailable after glycolytic inhibition by DCA (Stockwin et al, 2010). This also may explain the difference in sensitivity to DCA observed between two Warburg-like MM cell lines RPMI8226-TGL and JJN-3.

It has often been reported that increased ROS formation by DCA treatment can also profoundly impact mitochondrial membrane integrity causing a reduction in the $\Delta \psi_{\mathrm{m}}$ and subsequent initiation of apoptosis in several cancers (Bonnet et al, 2007; Michelakis et al, 2008, 2010; Stockwin et al, 2010; Ziebart et al, 2010). Therefore, we also investigated whether DCA treatment can induce a reduction in $\Delta \psi_{\mathrm{m}}$ in myeloma cells, using the cationic fluorescence indicator TMRE and flow cytometry. The cationic fluorescence indicator TMRE fluoresces upon accumulation within polarised mitochondrial membranes, and decreases in TMRE fluorescence intensity indicate a reduction in the $\Delta \psi_{\mathrm{m}}$ (Scaduto and Grotyohann, 1999; Ponomarev et al, 2004). It has been often overlooked that presence of dead (late apoptotic and necrotic) cells with ruptured mitochondrial membranes contribute to a decrease in TMRE fluorescence intensity (Bonnet et al, 2007; Wong et al, 2008; Madhok et al, 2010; Stockwin et al, 2010). To avoid data misinterpretation, we measured the TMRE signal in gated live cells (based on FSC and SSC characteristics). Using this approach, we did not detect any reduction in the $\Delta \psi_{\mathrm{m}}$ in viable myeloma cells following DCA treatment. As expected, a clear reduction in the TMRE signal was observed in gated dead cells defined as the FSC ${ }^{\text {low }}$ events (data not shown). Moreover, we discovered that DCA at doses of 10 and $25 \mathrm{~mm}$ increased the $\Delta \psi_{\mathrm{m}}$ in RPMI8226-TGL cells. Indeed, it is well characterised that mitochondrial ROS production is increased concomitantly with an increase in the $\Delta \psi_{\mathrm{m}}$. This occurs when respiration is low, the ubiquinone (CoQ) pool is highly reduced and the NADH/NAD ${ }^{+}$ ratio is high (Murphy, 2009). By regulating flux through PDH activation, DCA treatment would increase NADH and reduction of the CoQ pool. This coupled with only marginal increases in respiration would result in increased electron leak in the form of ROS.
Given that lactate is linked to resistance to chemotherapy treatment as it causes tumour acidifications (Gatenby and Gillies, 2004; McCarty and Whitaker, 2010), we asked whether inhibition of lactate production by DCA in Warburg MM cells enhance the effect of chemotherapy regiment with bortezomib. We show that DCA in combination with bortezomib improved the overall survival of myeloma-bearing mice transplanted with the Warburg MM cell line RPMI8226-TGL (Freeman et al, 2011) compared with control untreated mice. Also low doses of DCA in combination with bortezomib increased apoptosis and reduced viability of MM cell lines RPMI8226-TGL, JJN-3 and U266. These data are in line with previous reports suggesting that DCA acts synergistically with 5-fluourouracil in colorectal cancer cells (Tong et al, 2011), cisplatin in cervical cancer cells (Xie et al, 2010), decitabine in breast and prostate cancer cells (Babu et al, 2011), sulindac in lung and squamous cell carcinoma (Ayyanathan et al, 2012), omeprazole in fibrosarcoma and colon cancer (Ishiguro et al, 2012) and arsenic trioxide in breast cancer (Sun et al, 2011). In particular, the combination of DCA and omeprazole, a proton pump inhibitor, was the only significantly effective treatment reducing tumour volume in a HT108 fibrosarcoma-bearing mouse model compared with either DCA or omeprazole alone.

Our previous study establishes serum lambda chain levels as an effective measure of myeloma progression in myeloma-bearing mice (Freeman et al, 2011). Eighteen days of DCA treatment, alone or in combination with bortezomib, in contrast to bortezomib treatment alone, was not effective in reducing lambda chain levels and therefore the tumour burden in myeloma-bearing mice (Figure 5A). The possible changes in serum lambda chain levels during longer DCA treatment (alone or in combination with bortezomib) and their correlation with survival remain to be addressed.

Our study is the first report on the effect of DCA on myeloma using a range of myeloma cell lines and a clinically relevant myeloma-bearing mouse model (Freeman et al 2011). As myeloma remains an incurable disease, and new therapeutic options are desperately needed, it is a worthwhile endeavour to examine the potential efficacy of DCA combined with other active agents that induce profound apoptosis in malignant plasma cells (e.g., bortezomib). Our key finding, the combination of DCA with bortezomib significantly extends the survival of myeloma-bearing mice over bortezomib alone, provides preclinical support for the use of this drug combination against myeloma. Although the doses of DCA used in vivo are high, DCA is well tolerated in humans (Michelakis et al, 2008). This offers hope for a large group of myeloma patients for which treatment options may be limited.

\section{ACKNOWLEDGEMENTS}

This work was supported by the International Myeloma Foundation Brian D. Novis Senior Research Grant (L.C.). S.L.M is supported by a NHMRC Career Development Fellowship. S.V. is supported by Cancer Council Queensland.

\section{CONFLICT OF INTEREST}

The authors declare no conflict of interest.

\section{REFERENCES}

Ammini CV, Stacpoole PW (2003) Biotransformation, Toxicology and Pharmacogenomics of Dichloroacetate. In Natural Production of Organohalogen. pp 215-234. Springer-Verlag: Berlin/Heidelberg, Germany. 
Ayyanathan K, Kesaraju S, Dawson-Scully K, Weissbach H (2012) Combination of sulindac and dichloroacetate kills cancer cells via oxidative damage. PLoS ONE 7: e39949.

Babu E, Ramachandran S, CoothanKandaswamy V, Elangovan S, Prasad PD, Ganapathy V, Thangaraju M (2011) Role of SLC5A8, a plasma membrane transporter and a tumor suppressor, in the antitumor activity of dichloroacetate. Oncogene 30(38): 4026-4037.

Bonnet S, Archer SL, Allalunis-Turner J, Haromy A, Beaulieu C, Thompson R, Lee CT, Lopaschuk GD, Puttagunta L, Bonnet S, Harry G, Hashimoto K, Porter CJ, Andrade MA, Thebaud B, Michelakis ED (2007) A mitochondria- $\mathrm{K}+$ channel axis is suppressed in cancer and its normalization promotes apoptosis and inhibits cancer growth. Cancer Cell 11: 37-51.

Cairns RA, Bennewith KL, Graves EE, Giaccia AJ, Chang DT, Denko NC (2009) Pharmacologically increased tumor hypoxia can be measured by 18F-Fluoroazomycin arabinoside positron emission tomography and enhances tumor response to hypoxic cytotoxin PR-104. Clin Cancer Res 15: 7170-7174.

Cairns RA, Harris IS, Mak TW (2011) Regulation of cancer cell metabolism. Nat Rev Cancer 11: 85-95.

Cao W, Yacoub S, Shiverick KT, Namiki K, Sakai Y, Porvasnik S, Urbanek C, Rosser CJ (2008) Dichloroacetate (DCA) sensitizes both wild-type and over expressing $\mathrm{Bcl}-2$ prostate cancer cells in vitro to radiation. Prostate 68: $1223-1231$.

Chen Z, Lu W-G, Garcia-Prieto C, Huang P (2007) The Warburg effect and its cancer therapeutic implications. J Bioenerg Biomembr 39: 267-274.

Freeman LM, Lam A, Petcu E, Smith R, Salajegheh A, Diamond P, Zannettino A, Evdokiou A, Luff J, Wong P-F, Khalil D, Waterhouse N, Vari F, Rice AM, Catley L, Hart DNJ, Vuckovic S (2011) Myeloma-Induced alloreactive $\mathrm{t}$ cells arising in myeloma-infiltrated bones include double-positive CD8 + CD4 + T Cells: evidence from myeloma-bearing mouse model. J Immunol 187: 3987-3996.

Gatenby RA, Gillies RJ (2004) Why do cancers have high aerobic glycolysis? Nat Rev Cancer 4: 891-899.

Ghias K, Ma C, Gandhi V, Platanias LC, Krett NL, Rosen ST (2005) 8-Aminoadenosine induces loss of phosphorylation of p38 mitogen-activated protein kinase, extracellular signal-regulated kinase 1/2, and Akt kinase: role in induction of apoptosis in multiple myeloma. Mol Cancer Ther 4: 569-577.

Gogvadze V, Zhivotovsky B, Orrenius S (2010) The Warburg effect and mitochondrial stability in cancer cells. Mol Aspects Med 31: 60-74.

Heshe D, Hoogestraat S, Brauckmann C, Karst U, Boos J, Lanvers-Kaminsky C (2011) Dichloroacetate metabolically targeted therapy defeats cytotoxicity of standard anticancer drugs. Cancer Chemother Pharmacol 67(3): 647-655.

Ishiguro T, Ishiguro M, Ishiguro R, Iwai S (2012) Cotreatment with dichloroacetate and omeprazole exhibits a synergistic antiproliferative effect on malignant tumors. Oncol Lett 3: 726-728.

Jones RG, Thompson CB (2009) Tumor suppressors and cell metabolism: a recipe for cancer growth. Genes Dev 23: 537-548.

Kerr DS (2010) Treatment of mitochondrial electron transport chain disorders: a review of clinical trials over the past decade. Mol Genet Metab 99: 246-255.

Madhok BM, Yeluri S, Perry SL, Hughes TA, Jayne DG (2010) Dichloroacetate induces apoptosis and cell-cycle arrest in colorectal cancer cells. Br J Cancer 102(12): 1746-1752.

McCarty MF, Whitaker J (2010) Manipulating tumor acidification as a cancer treatment strategy. Altern Med Rev 15: 264-272.

McGee SL, Sadli N, Morrison S, Swinton C, Suphioglu C (2011) DHA protects against zinc mediated alterations in neuronal cellular bioenergetics. Cell Physiol Biochem. 28: 157-162.

Michelakis ED, Sutendra G, Dromparis P, Webster L, Haromy A, Niven E, Maguire C, Gammer T-L, Mackey JR, Fulton D, Abdulkarim B, McMurtry MS, Petruk KC (2010) Metabolic modulation of glioblastoma with dichloroacetate. Sci Transl Med 2: 31ra34.

Michelakis ED, Webster L, Mackey JR (2008) Dichloroacetate (DCA) as a potential metabolic-targeting therapy for cancer. Br J Cancer 99: 989-994.
Murphy MP (2009) How mitochondria produce reactive oxygen species. Biochem J 417: 1.

Seth P, Grant A, Tang J, Vinogradov E, Wang X, Lenkinski R, Sukhatme VP (2011) On-target Inhibition of tumor fermentative glycolysis as visualized by hyperpolarized pyruvate. Neoplasia 13: 60-71.

Ponomarev V, Doubrovin M, Serganova I, Vider J, Shavrin A, Beresten T, Ivanova A, Ageyeva L, Tourkova V, Balatoni J, Bornmann W, Blasberg R, Gelovani Tjuvajev J (2004) A novel triple-modality reporter gene for whole-body fluorescent, bioluminescent, and nuclear noninvasive imaging. Eur J Nucl Med Mol Imag 31: 740-751.

Scaduto RC, Grotyohann LW (1999) Measurement of mitochondrial membrane potential using fluorescent rhodamine derivatives. Biophys J 76: 469-477.

Shanmugam M, Mcbrayer SK, Qian J, Raikoff K, Avram MJ, Singhal S, Gandhi V, Schumacker PT, Krett NL, Rosen ST (2009) Targeting glucose consumption and autophagy in myeloma with the novel nucleoside analogue 8-aminoadenosine. J Biol Chem 284: 26816-26830.

Stjernholm RL (1967) Carbohydrate metabolism in leukocytes. VII. Metabolism of glucose, acetate, and propionate by human plasma cells. J Bacteriol 93: 1657-1661.

Stockwin LH, Yu SX, Borgel S, Hancock C, Wolfe TL, Phillips LR, Hollingshead MG, Newton DL (2010) Sodium Dichloroacetate (DCA) selectively targets cells with defects in the mitochondrial ETC. Int J Cancer 127(11): 2510-2519.

Suganuma K, Miwa H, Imai N, Shikami M, Gotou M, Goto M, Mizuno S, Takahashi M, Yamamoto H, Hiramatsu A, Wakabayashi M, Watarai M, Hanamura I, Imamura A, Mihara H, Nitta M (2010) Energy metabolism of leukemia cells: glycolysis versusoxidative phosphorylation. Leuk Lymphoma 51: 2112-2119.

Sugden MC, Holness MJ (2003) Recent advances in mechanisms regulating glucose oxidation at the level of the pyruvate dehydrogenase complex by PDKs. Am J Physiol Endocrinol Metab 284: E855-E862.

Sun RC, Board PG, Blackburn AC (2011) Targeting metabolism with arsenic trioxide and dichloroacetate in breast cancer cells. Mol Cancer 10: 142 .

Sun RC, Fadia M, Dahlstrom JE, Parish CR, Board PG, Blackburn AC (2010) Reversal of the glycolytic phenotype by dichloroacetate inhibits metastatic breast cancer cell growth in vitro and in vivo. Breast Cancer Res Treat 120: 253-260.

Tong J, Xie G, He J, Li J, Pan F, Liang H (2011) Synergistic antitumor effect of dichloroacetate in combination with 5-fluorouracil in colorectal cancer. J Biomed Biotechnol 2011: 1-7.

Wong JYY, Huggins GS, Debidda M, Munshi NC, de Vivo I (2008) Dichloroacetate induces apoptosis in endometrial cancer cells. Gynecol Oncol 109: 394-402.

Wu M, Neilson A, Swift AL, Moran R, Tamagnine J, Parslow D, Armistead S, Lemire K, Orrell J, Teich J, Chomicz S, Ferrick DA (2007) Multiparameter metabolic analysis reveals a close link between attenuated mitochondrial bioenergetic function and enhanced glycolysis dependency in human tumor cells. Am J Physiol Cell Physiol 292: C125-C136.

Xie J, Wang BS, Yu DH, Lu QH, Ma J, Qi H, Fang C, Chen HZ (2010) Dichloroacetate shifts the metabolism from glycolysis to glucose oxidation and exhibits synergistic growth inhibition with cisplatin in HeLa cells. Int J Oncol 38: 409-417.

Yeluri S, Madhok BM, Jayne DG (2012) New horizons in cancer therapy: manipulating tumour metabolism. Biomed Res 23: 17-23.

Ziebart T, Walenta S, Kunkel M, Reichert TE, Wagner W, Mueller-Klieser W (2010) Metabolic and proteomic differentials in head and neck squamous cell carcinomas and normal gingival tissue. J Cancer Res Clin Oncol 137: 193-199.

This work is published under the standard license to publish agreement. After 12 months the work will become freely available and the license terms will switch to a Creative Commons AttributionNonCommercial-Share Alike 3.0 Unported License. 